\title{
Review of Farmer Training Centers (FTCs) Based Training in The Case of Ethiopia Country
}

\author{
Suleymen Abdureman Omer \\ Rural Development and Agricultural Extension Department, Research Affairs, Haramaya University, P.O.Box \\ 138, Dire Dawa, Ethiopia
}

\begin{abstract}
Farmers Training Center (FTC) of the country was established in the year 1980 at Agarfa in Bale, Oromia Region, Ethiopia country. Its main objective was the quick transfer of technology to the rural population so as to raise the quality of agricultural production, the living condition of the rural community and the country as a whole. Effectiveness of FTC based training on agricultural technology adoption and practice change is operationalized as the application of knowledge acquired from the training. It is the transfer of learning. Training is a prerequisite to decrease the complexity of the technology and used to disseminate knowledge and skill to the farming community. Moreover, field visit, tour and demonstration upgrade farmers' knowledge and skill. Farmer training is a type of education that most often takes place outside formal learning institutions. It differs from education in schools because it is geared towards adult learning. Training has experienced a rapidly changing scenario especially from past decade. The present study was carried out with the aim of assessing review of farmer training centers (FTCs) based training in the case of Ethiopia country. Analysis of the various aspects of training should be undertaken by organizations, stakeholders, and beneficiaries. Thus, deciding on what and how to evaluate and by who are critical parts of the evaluation process.
\end{abstract}

Keywords: Effectiveness, Evaluation, Farmer Training Center, Relevance, Training.

DOI: $10.7176 / \mathrm{DCS} / 11-3-03$

Publication date:March $31^{\text {st }} 2021$

\section{Introduction}

\subsection{Background and Context of Basic Concept and Definition of Training}

According to Burton (2014), training was defined as the process of providing knowledge, skills and bringing about desired changes in attitudes in order to improve the competence of people being trained. Van Dersal (2012) also defined training as the process of teaching, informing, or educating people so that (1) they may become as well qualified as possible to do their job, and (2) they become qualified to perform in positions of greater difficulty and responsibility.

Training is a type of learning intervention that can improve workplace performance and facilitate the introduction of new job responsibilities by improving workers' knowledge, practical skills and attitudinal behaviors. Training is appropriate only when a performance gap is due to a lack of knowledge and skills. Because performance gaps often have multiple causes, the situation may require several integrated interventions. Farmers' participation on various areas of human resource development is a crucial tool to bring voluntary behavioral change (change in knowledge, attitudeand practice). However, literature review indicated that majority of the farmers in rural area have not participated in most of useful trainings (Seyoum, 2013).

Usually an organization facilitates the employees' learning through training so that their modified behavior contributes to the attainment of the organization's goals and objectives. Human Resource Development (HRD) is one of the many strategies in achieving the vision for development in any country. Training can be one of the best ways to develop human resources. It aims to develop people's potential and enable them to use this potential towards the achievement of their vision of self-reliance and self-sufficiency. It covers the development of peoples' knowledge, skill and attitude as they deal with their day-to-day life situation (IIRR, 1997; Marissa, 2018).

Farmer training is a type of education that most often takes place outside formal learning institutions. It differs from education in schools because it is geared towards adult learning. Mature adults are self-directed and sufficient in most aspects of their lives.Adults tend to resent educators that fail to take this fact into account. They do not appreciate being talked down to or having their autonomy restricted in ways that show a lack of respect (Hassen and Amdissa, 1993).

Filippo (1961) as cited in Burton et al., 2014) differentiated between educations and training, locating these at the two ends of a continuum of personnel development ranging from a general education to specific training. While training is concerned with those activities which are designed to improve human performance on the job that employees are at present doing or are being hired to do, education is concerned with increasing general knowledge and understanding of the total environment.

Education is the development of the human mind and it increases the powers of observation, analysis, integration, understanding, decision making, and adjustment to new situations. The goal of training is to improve behavioral change/ performance. Education also provides knowledge and skills and brings about changes in 
attitudes. However, training differs from education in a number of ways. Training is short term, narrowly focused and specific, usually designed to meet a specific needs and has immediate application. Whereas education is long term, broadly focused, and usually aimed at preparing people for the future (Youdeowei and Kwarteng, (2015).

In addition, extension education is generally the main, if not the only means for farmers' education in developing countries and is a specialized form of the broader concept of adult education (Arnon, 1981 cited inWuletaw M., 2014). Training is a prerequisite to decrease the complexity of the technology and used to disseminate knowledge and skill to the farming community. Moreover, field visit, tour and demonstration upgrade farmers' knowledge and skill.

According to Seyoum, (2013) the basic philosophy of extension education is directed towards changing the outlook of man by educating him. Its primary aim is, therefore, to transform people by bringing about desired changes in their knowledge, attitudes and skills. Besides formal training, non-formal and informal learning opportunities are important in enhancing the capacity of farmers. Formal training is defined as any form of training for which the content and learning aims have been defined.This usually means training is based on well-defined curricula, either within or without an institution, with or without guidance from a teacher or trainer. On the other hand, informal training is any form of training for which the content and the learning aims are not defined. Hence, this encompasses on the job-training, traditional apprenticeships as well as self-organized learning. It includes any form of learning that happens "on the side", i.e. through activities whose primary aim is not learning (Wuletaw, 2014).

The effect of formal (any form of training for which the content and learning aims have been defined) and informal training (any form of training for which the content and learning aims have not been defined)on farmers income levels have long been analyzed in economics literature. Specifically, Anderson (2017) suggests that education and training are essential for managing and promoting the changes that farmers are to be sustainable. Similarly, Kilpatrick (2013) showed that farm businesses with managers who had participated in more education and training is more profitable. Similarly awareness of possible innovations through mass media and contacts with expert advisers is proved to be leading superior outcomes (Tesfaye, 2016).

The basic definition of evaluation is a process to determine the relevance, effectiveness and impact of activities in light of their objectives (Raab et al., 1987 cited in Wuletaw, 2014). And also they defined the term of training evaluation as " a systematic process of collecting information for and about a training activity, which can then be used for guiding decision making and for assessing the relevance and effectiveness of various training components".Evaluation is about assessing the effectiveness of the various aspects of training. It is an interactive and systematic process of investigating the value and quality of a program in which various stages of training are appraised from the viewpoint of their adequacy and contribution to achieve the training objectives. To make the training process effective, the stages and the sub- stages of the cycle of training should be treated in the way that makes them productive and fruitful. Analysis of the various aspects of training should be undertaken by organizations, stakeholders, and beneficiaries. Thus, deciding on what and how to evaluate and by who are critical parts of the evaluation process (Gboku and Lekoko, 2014).

According to the study of Luchia, (2015) most training follow highly theoretical and lecture type of methodology. Hence, redirecting in mixing both theory and practice with the help of audio visual aids and different demonstration methods should be future assignment as most of the farmers of our country are illiterates.

Training need assessment is one of the crucial steps towards identifying the area of farmers' interest, design and develop curriculum that can best suit to the existing real conditions of farmers. It is important to remember that participation and involvement of the trainee is an essential part, whatever the method or combination of methods chosen (Biruk, 2010).

\section{Result and discusion}

\subsection{Review of Relevance of Farmer Training Centers (FTCs)-based training}

Relevance is a concern with the degree to which the rationale, objectives and expected impact of a training activity are achieved or remain pertinent, valid and significant with regard to long-range objectives or identified priority needs and concerns (FAO, 2014; Bekelech, 2014).

Miller and Osinski (2012) defined relevance, in adult training context, as identifying and understanding the training content to be relevance-oriented in a sense that, the theories and concepts must be related to a setting familiar to training participants. Learners must see a reason for learning something. Learning has to be applicable to their work or other responsibilities to be of value to them. Relevance is closely related to the problem being addressed and target group under consideration. And also relevance is primarily assessed through peer or expert review and beneficiary assessment.

The relevance of FTC-based training to the needs and constraints of farm households with different capabilities, resource endowment and with male-headship and female-headship can be assessed from different dimensions. In the first place, whether or not the training needs of farm households with different capabilities, resources headship and livelihood options was properly conducted determine the extent to which farmers' training 
addresses diversified needs. Secondly, the relevance of farmers training can be seen in terms of location, method of delivery and the availability of appropriate audiovisual \non-audio-visual aids, infrastructure and facilities for practical learning. Monitoring and evaluation processes are important to ensure the relevance of training along with appropriate section of trainees (Luchia, 2015).

The first most essential component of the process in developing relevant farmer training program is finding out about the people to be trained and the type of training they need. The issue of developing appropriate content is critical to extension process; the performance of extension systems depends, in large part, on the appropriateness of its message (Campbell and Barker, 1997; as cited in Tsion, 2010).

According to the study of Kefyalew (2006), training is needed to be essential components of designed interventions; a uniform system of research is to explain how training is made active and to indicate how resources for training should be organized. This section aimed at examining farmers' assessment of the relevance of FTCbased training in terms of attributes that are theoretically known to be determinants of the relevance of not just the content but also the process of training.

On the other hand, indicators of the relevance of farmer training can be categorized here under, which includes; schedule and timing issues- Timeliness of training, suitability of the timing and the schedule of the training, for trainees. physical environment of the training- Training environment and teaching aids $\backslash$ methods at FTC, adequacy and quality of training facilities, suitability of the venue and the place where sessions were conducted. Learning objectives of the training in addressing farmers felt need- Practices to farmers pressing problems and needs, the extent to which the learning experience reflected and rooted in the local context and indigenous knowledge. Trainer's ability- Trainers' (DAs) knowledge, practical skills and communication skill of trainers.

\subsection{Review on The Effectiveness of farmer training centers (FTCs)-based training 2.2.1. FTCs- based training purpose and operation}

The first Farmers Multipurpose Training Center (FMPTC) of the country was established in the year 1980 at Agarfa in Bale, Oromia Region. Its main objective was the quick transfer of technology to the rural population so as to raise the quality of agricultural production, the living condition of the rural community and the country as a whole. Realizing training of farmers by government had started FTCs programs, and planned to establish about 18 thousand FTCs throughout the country to enhance the knowledge base of farmers and to provide the institutional framework for increasing the efficiency and effectiveness of agricultural advisory services. Almost every woreda in the country has been constructing FTCs; and some woredas have already constructed the required number of FTCs. FTC were expected to serve as centers of extension service and information, places where modular training to farmers from three up to six months to be given, and also serve as sources of advice on projects. Local communities are expected to gradually takeover ownership and management responsibility for the functioning of the FTCs (MoARD, 2005; Birhanu et al., 2016).

The FTCs were expected to play an active role in linking farmers with other institutional support services such as input supply, credit, co-operative promotion, and agricultural produce marketing. To bring transformation in agricultural extension service, farmers must be trained to improve their knowledge, skill and attitude towards deciding in their own affairs, access to information, exposure to improved farming and living practices (Birhanu et al., 2016).

According to Wuletaw, (2014) report indicates that private and public sector should be reconfigured into training policy analysis so as to participate and make integration. For instance, FTCs can be run by state universities, colleges, bilateral and multilateral NGOs, and industries. FTCs also should be conceived as rural vocational training centers to impact knowledge and skills to farmers so that they could increase their productivity and efficiency.

Formal and non-formal trainings are equally important. But farmers need to have an opportunity to learn nonformal training at their farming community through different training programs. And thus, the government has launched potential development goals including modular training, extension training and information service at FTC. Many efforts have been made by different organization to strengthen this program such as the training of extension agents, newly established and building FTCs (MoARD, 2015).

According to farmer instructional development in the Netherlands Ministry of Foreign Affairs defines Institutional development as a process that involves creating people's awareness in activities they are involved. Farmer institutional development will be the core component of intervention in terms of the trainings. The FTCs are expected to serve as hubs for farmers to receive advisory services, knowledge and information, training, and demonstrations on improved and sustainable farm management practices (Gebremedhin et al., 2016; Mogues et al., 2009; IFPRI, 2010).

According to Ethiopian Ministry of Agriculture operational manual/procedures, the training at the FTC will focus on two major categories: modular training and farmers training on agricultural extension packages.

1) Extension package training: Training on agricultural extension package is short-term training provided to all farmers for mass mobilization in the area of agricultural extension package programs. The training is prepared to 
minimum and family package users, and is planned to cover both theoretical and practical aspects of the sector's activity. It is delivered to farmers by development workers on the demonstration trial of the training center and on the fields of model farmers. The period of the training usually ranges from 3-15 days, though it may sometimes be extendedto 20 days depending on the existing situation of the locality, and 15-20 trainees will take part in one round (MoA, 2017). Awareness creation of farmers can be created through agricultural package training at FTCs level. Orientation about a given technologies, skill trainings and other types of meetings can be delivered in FTCs. 2) Modular training: - modular training is specialized training for farmers starting from grade four working in agriculture who owns farm land in which all agricultural extension activities will give due emphasis to gender integration. In modular training, the duration of training provided for each profession will be 3-6 months. Depending on the type of profession or module, 2 training periods/ semesters will be arranged each year. A class room is arranged to accommodate only 20-30 trainees. The number is limited, because an increase in the number of trainees/ participants above the maximum has an adverse effect on the effectiveness of the training. Strengthen need based and practical training to farmers (MoA, 2017).

Farmer training in FTCs should focus on the priority needs and existing gaps as identified together with farmers as well as by taking into consideration emerging needs of the government, agro-processing and investors. Farmers' training by DAs must also adapt to adult and experiential learning methodologies. In most cases, farmers learn more when the training is provided in a two-way learning method, supported with relevant audio-visuals and consider farmers' indigenous knowledge and when their experiences are shared among the participants (Bergaet al., 2013).

The following principles should guide development and delivery of training: emphasize practical skill trainings should be $70 \%$ practical and $30 \%$ theory, adapt to circumstances organize trainings based on convenient timing to male, female and youth farmers, seasonal activity and specific agro-ecologies, use well-qualified and experienced trainers who build farmer's interest in FTCs. Evaluate regularly conduct training method and relevance assessment during and after the training (MoANR, 2017).

According to the study of Luchia, (2015) it indicated that FTC based training is relevant in terms of timeliness and scheduling specially for male farmers, teaching aids, location of training, the communication and practical skills of the trainers were also relevant to the farmers. However, FTC based training lacked training need assessment, less in adequacy and quality of training facilities and being more theoretical and lecture type in methodology, limited use of' indigenous knowledge, less female participation and follow up after the training were the major deficiencies. Therefore, it is recommended that policy aimed at FTC based training in the area could be successful if there is proper training need assessment, increases females participations, gives due focus on practice based training, make uses of indigenous knowledge, regular follow up mechanism and the result of this study are taken in to consideration and they can experience sharing mechanisms among FTCs so as to cross fertilize the successful results throughout the study area and lesson are developed and institutionalized (Luchia, 2015).

According to Seyoum (2013), training need assessment (TNA) is a pre-request for successful and outcome oriented training program. Trainers should aim at extending the people's active participation in need assessment method through discussions, surveys, questionnaires, and interviews. By involving the people in the process of development rather than just the end product, their critical awareness and their ability to solve problems will be mobilized. This means that there must be a training need assessment(Seyoum, 2013).

FTCs need to have basic infrastructure and facilities for proper functioning. The full list of facilities required is outlined in the FTC guideline. DA housing and offices; classrooms with appropriate training materials and furniture; farm implements for crops and livestock production; tools required to properly manage NRM; workshops, a permanent exhibition center; demonstration plots; meteorological information center; and ICT facilities are among the major ones. FTCs with a good set of facilities will improve FTCs' performance and attract farmers. FTCs should be capacitated in accordance with FTC classification shown Table 1 will guide the types of resources required to upgrade the FTCs to the next functionality level (MoANR, 2017). 
Table 1: Classification FTCs based on functionality levels.

\begin{tabular}{|c|c|c|}
\hline Basic & Intermediate & Advanced \\
\hline At least 3 DAs, & $\begin{array}{ll}\text { Active } & \text { communitymanagement } \\
\text { structure, }\end{array}$ & $\begin{array}{l}\text { Revenue generation for self- } \\
\text { sustainability, }\end{array}$ \\
\hline $\begin{array}{l}\text { Moderately } \\
\text { furnishedFTCbuilding, }\end{array}$ & $\begin{array}{l}\text { Adequate level of facilities, } \\
\text { /equipment in place for FTC training } \\
\text { and demonstrations, }\end{array}$ & $\begin{array}{l}\text { Active linkage with cooperatives, micro- } \\
\text { finance institutions (MFIs), research } \\
\text { centers and ATVETs and farmers } \\
\text { innovations groups }\end{array}$ \\
\hline $\begin{array}{l}\text { Agro-ecology based FTCs } \\
\text { anddemonstration plot, } \\
\text { FTC training and } \\
\text { Demonstration plan, } \\
\text { FTC management } \\
\text { Committee and operational } \\
\text { guideline }\end{array}$ & $\begin{array}{l}\text { Trainings and demonstrations at least } \\
\text { in three thematic areas, } \\
\text { FTC trainings efficiently linked to } \\
\text { demonstrations, } \\
\text { FTC training materials, manuals and } \\
\text { guidelines available. }\end{array}$ & $\begin{array}{l}\text { Availability of operationalresource } \\
\text { centers (connectivity, information), } \\
\text { Ability to handle level } 1 \text { and } 2 \text { training. }\end{array}$ \\
\hline
\end{tabular}

Source: MoANR, 2017.

\subsubsection{Effectiveness of farmer training at FTCs}

Effectiveness of a program or service is a measure of how well the outputs of a program or service achieve the stated objectives (desired outcomes) of that program or service. Effectiveness refers to the intervention's ability to do more good than harm for the target population in a real world setting. In general, effectiveness is the extent to which stated objectives are met the policy achieves what it intended to achieve. The goal can be as broad or as narrow as is deemed appropriate a continuum exists, ranging from achieving very specific outputs (such as 'increasing the number of solar heating panels installed in new houses') to very general outcomes (such as 'improving the environment' or even 'improving community living standards or wellbeing')(Bradbury,2013).

Effectiveness refers to a measure of the extent to which a training activity achieves its objectives. Objective is a goal or end which describes what is to be accomplished if the training activity is to be effective (FAO, 2014; Bekelech, 2014).

Kirkpatrick, (2014) suggests such thought and emphasis need to be given in designing trainings to make sure that the programs are effective and relevant. An effective training need to be problem oriented, need based, with measurable and achievable learning objectives that show changes in knowledge, skill and attitudes, changes in job performance and outcomes within given time; implemented in conducive adult learning requirements (methods and materials), with continuous follow-up where activities and results are monitored, reviewed and evaluated for further improvement of the whole system.

In converting needs into objectives, three areas of performance may be identified; skills, knowledge and attitude. Skills-related objectives indicate what the trainee can do, demonstrate or perform as result of the training. Knowledge-related objectives refer to the participants' ability to identify, define or describe given concepts as a result of the training. Attitude- objectives are less easy to measure although it may be useful to make explicit the desired attitudinal change. The trainer and the trainees should understand and agree on the objectives of the training course. It is a useful technique for the trainer to refer to the course objectives at key times in the course to ensure that the trainees recognize how the training is progressing towards achieving the objectives. When participants know what is expected of them they can organize their efforts more effectively (Swanson et al., 2016).

Effectiveness of FTC based training on agricultural technology adoption and practice change is operationalized as the application of knowledge acquired from the training. It is the transfer of learning. Practices of farmers were evaluated based on their responses on the application of recommended technologies (Luchia, 2015).

According to Norman, (2016), training programs are designed to change trainee knowledge, attitudes and skills. In terminal evaluation want to see if our training has accomplished this goal and to what degree. The most common method used in a terminal evaluation is to test trainee knowledge, attitudes and skills. Each of the three kinds of learning can be measured through some form of testing. Test results are then compared either with predetermined standards (as specified in objectives), with entry level knowledge (as measured by a pre-test), or through certification tests where standards are set by someone else.

The common procedures in terminal evaluation are; (I) develop or adapt existing data collection questionnaire, decide what type of test items should be included; (II) Administer the instruments, the way in which these instruments are administered varies with many factors, such as audience characteristics (age, sex, education level etc.), objectives being assessed, and type of assessment instrument; (II) Interpret the results. Anthony (2013) outlined commonly used Teacher-Made Test items to measure knowledge, attitude and practice levels. TeacherMade Test for measuring knowledge, Likert type of attitude scale and practice test for measuring practice level of sample households was adopted. 


\section{Conclusion}

This study was attempt to review of assessed the relevance and effectiveness of FTCs-based farmer training. The first Farmers Multipurpose Training Center (FMPTC) of the country was established in the year 1980 at Agarfa in Bale, Oromia Region. Its main objective was the quick transfer of technology to the rural population so as to raise the quality of agricultural production, the living condition of the rural community and the country as a whole. Realizing training of farmers by government had started FTCs programs, and planned to establish about 18 thousand FTCs throughout the country to enhance the knowledge base of farmers and to provide the institutional framework for increasing the efficiency and effectiveness of agricultural advisory services. Training is a prerequisite to decrease the complexity of the technology and used to disseminate knowledge and skill to the farming community. Moreover, field visit, tour and demonstration upgrade farmers' knowledge and skill.

Farmer training is a type of education that most often takes place outside formal learning institutions. The basic definition of evaluation is a process to determine the relevance, effectiveness and impact of activities in light of their objectives. And also they defined the term of training evaluation as " a systematic process of collecting information for and about a training activity, which can then be used for guiding decision making and for assessing the relevance and effectiveness of various training components". Evaluation is about assessing the effectiveness of the various aspects of training. It is an interactive and systematic process of investigating the value and quality of a program in which various stages of training are appraised from the viewpoint of their adequacy and contribution to achieve the training objectives. To make the training process effective, the stages and the sub- stages of the cycle of training should be treated in the way that makes them productive and fruitful. Analysis of the various aspects of training should be undertaken by organizations, stakeholders, and beneficiaries.

Farmer training in FTCs should focus on the priority needs and existing gaps as identified together with farmers as well as by taking into consideration emerging needs of the government, agro-processing and investors. Farmers' training by DAs must also adapt to adult and experiential learning methodologies. In most cases, farmers learn more when the training is provided in a two-way learning method, supported with relevant audio-visuals and consider farmers' indigenous knowledge and when their experiences are shared among the participants (Bergaet al., 2013). The following principles should guide development and delivery of training: emphasize practical skill trainings should be $70 \%$ practical and $30 \%$ theory, adapt to circumstances organize trainings based on convenient timing to male, female and youth farmers, seasonal activity and specific agro-ecologies, use well-qualified and experienced trainers who build farmer's interest in FTCs. Evaluate regularly conduct training method and relevance assessment during and after the training.

\section{References}

ATA (Agricultural Transformations Agency) 2017. Ethiopia's Agricultural Extension Strategy. Addis Ababa.

Barbazette, J., 2016. Training Needs Assessment, Methods, Tools, and Techniques. Published by Pfeiffer, San Francisco, USA.

Bekelech T., 2014. The Effectiveness of Farmer Training Centers in the Economic Life of Rural Adults: The case of Oromia National Regional States of South West Shoa Zone Wonchi woreda. An MSc Thesis presented to School of Graduate Studies of Addis Ababa University, Ethiopia.

Berga Lemaga, D. Borus, R. Kakuhenzire, G. Woldegiorgis, D. Tibanyendera, J. Nshimiyimana, E. SchulteGeldermann, and I. Barker, (2013). Capacity building: A basis for Technology adoption and sustainable potato production in Eastern Africa. Act Hort. (ISHS) 1007:649-655. http://www.actahort.org/books/1007/1007_75.htm.

Birhanu Gebramedhin, Hoekstra D. and AzägeTegegne 2016. Commercialization of Ethiopian agriculture: Extension Service from input supplier to knowledge broker and facilitator. IPMS of Ethiopian Farmers Project Working paper ILRI, Nairobi. 33pp.

Biruk T., 2010. Effectiveness of Modular Training at Farmers Training Centers: The Case of Mi'esoWoreda, Oromia Region. An MSc Thesis presented to School of Graduate Studies of Haramaya University, Ethiopia.

Bradbury, Productivity Commission May 2013. On efficiency and effectiveness: some definitions, Staff Research Note, Canberra, Common wealth of Australia.

Caffarela, R.S., 2012. Planning Programs for Adult Learners.A practical guide for educators, trainers and staff developers.(Second edition).John Wiley \& Sons, Inc. San Francisco.

Feder, G., R. Birner, and J. Anderson. (2011). "The Private Sector's Role in Agricultural Extension Systems: Potential and Limitations.' Journal of Agribusiness in Developing and Emerging Economies 1 (1): 31-54. Doi:10.1108/20440831111131505

Gebremedhin B., Jemaneh S., Hoekstra, D., Anandajayasekeram, P. (2012). A guide to market oriented extension services with special references to Ethiopia. IPMS (Improving Productivity and Market Success) of Ethiopian Farmers Project. Nairobi. ILRI.Pp 101.

Habtemariam Abate. (2013). Habtemariam Abate (2007). Review of Extension Systems Applied in Ethiopia with Special emphasis to the Participatory Demonstration and Training Extension System. Addis Ababa, Ethiopia. 
Hassen Hakimian and AmdisaTeshome, 2013. Trainers Guide: Concepts, Principles, and Methods of Training, With Special Reference to Agricultural Development. FAO, Rome.407p.

International Institute for Rural Reconstruction (IIRR), 2017. Manual for Training of Trainers for Sustainable Agriculture Course. Philippines.

IRRI. 2012. Training and technology transfer course performance objectives manual. Manila: International Rice Research Institute.

Kamariah Dola, 2011. Investigating Training Impact on Farmers' Perception and Performance. International Journal of Humanities and Social Science Vol. 1 No. 6

Kilpatrick S., 2017. Education and Training: Impacts on profitability in agriculture. In New Zealand, Journal of vocational Education Research. 5, 2, pp. 11-36.

Kirkpatrick, D. L., 2014. Evaluating Training Programs.Berrett-Koehler Publishers, Inc. USA.

Kefyalew Worku, 2006. Evaluation of farmers' Training programs: the Case of Eastern Harerghe (Babile and Hudaneworedas). A M.Sc. Thesis Presented to the School of Graduate Studies of Haramaya University. 74p.

Lemma T. Sehai, E. and Hoekstra D.2010. Status and capacity of FTCs in improving productivity and Market Success Pilot Learning woredas. ILRI, Addis Ababa

LuchiaTekle, 2015. Analysis of Positive Deviance Farmer Training Centers in Northern Ethiopia. American Journal of Rural Development, vol. 3, no. 1 (2015): 10-14. doi: 10.12691/ajrd-3-1-3.

Marissa, B., 2018. Espeneli for the Training of Trainers for Sustainable Agriculture Course.IIRR Headquarters, Silang, Cavite, Philippines.

Mellor, J. W. (2014). High rural population density Africa - What are the growth requirements and who participates? Food Policy DOI: 10.1016/j.foodpol.2014.03.002

Merihun Fikru Meja and Endrias Geta, 2017.Analyzing Farmers' Training Centers through Integrated Innovative Capacity Building and Technologies Transfer; a Case Study of Damot Gale District Woliata Zone, Ethiopia.International Journal of Environmental Sciences.Vol. 6 No. 4. 2017. Pp. 94-100

Miller J. A, and Osinsiki D. M., 2012.Training Needs Assessment.SHRM Training and Development Committee, SPHR Press, UK.Society for Human Resource Management (SHRM).

MoARD, 2017.Working Guide line of Farmers Training Centers, Addis Ababa.

MoARD (Ministry of Agriculture and Rural development), 2008. Guideline on scale up and scale out of agricultural technologies. Addis Ababa, Ethiopia.

MoA, 1980a. Southern zone farmer's multi-purpose Training Center Project Proposal. Vol.1, MoA Publication, Addis Ababa, Ethiopia.

MoA, 2017. Farmers Training Centers project Proposal. MOA publication, Addis Ababa, Ethiopia.

MoANR (Ministry ofAgriculture and Natural Resource), 2017. Ethiopia's Agricultural Extension Strategy, Addis Ababa.

Murshed-E-Jahan and Pemsl, 2011. The impact of integrated aquaculture-agriculture on small- scale farm sustainability and farmers livelihoods: Experience from Bangladesh. Agricultural Systems.

Oreszczyn, S., Lane, A. Carr, S. (2010). The role of networks of practice and webs of influencers on farmers' engagement with and learning about agricultural innovations. Journal of Rural Studies 26(2010) 404-417.

Ousman Surur, 2007. Effectiveness of Agricultural Training Development Program: the case of teff and livestock farmers of Alabaworeda. A M.Sc. Thesis Presented to the School of Graduate Studies of Haramaya University. $139 \mathrm{p}$.

Raab, R.T., Swanson, B.E., Wentling, T.L. and dark, C.D., 2017. A trainer's guide to evaluation. Rome: FAO.

Rama, B.R., Etling, A.W. and Bowen, B.E., 2017. Training of Farmers and Extension Personnel. In R.K. Samanta (Ed.), Extension Strategy for Agricultural Development in 21 st Century. Mattila Publications. New Delhi.

Seyoum E., (2013). Performance of Farmers Training Centers in South Wollo Zone: with Special Reference to KaluWoreda, Amhara Regional State. An M.Sc thesis presented to Indira Gandhi National Open University (IGNOU).

Tefera, T. L., Sehai, E., \& Hoekstra, D. (2011). Status and Capacity of Farmer Training Centers (FTCs) in the Improving Productivity and Market Success (IPMS) Pilot Learning woredas (PLWs).ILRI, Addis Ababa, Ethiopia.

Tsion Tesfaye, 2010. Effectiveness of farmers training offered by Ethiopian Institute of Agricultural Research to farmers: the case of Holeta, Melkassa and DeberZiet agricultural Research Centers. An MSc Thesis Presented to the School of Graduate Studies of Haramaya University.76p.

Wuletaw Mekuria, 2014. "Effectiveness of Modular Training at Farmers' Training Center: Evidence from Fogera District, South Gondar Zone, Ethiopia.” American Journal of Rural Development, vol. 2, no. 3 (2014): 4652. Doi: 10.12691/ajrd-2-3-2. 